\title{
A FORMAÇÃO DOS PROFESSORES E A PRÁTICA REFLEXIVA: \\ OS CANAIS DE PERCEPÇÃO NO ENSINO DO TEATRO \\ Robson Rosseto ${ }^{1}$
}

Resumo

Este artigo discute a ação reflexiva do professor de teatro. O potencial da inclusão de estudos sobre os canais de percepção (auditivo, sinestésico e visual) é considerado como parte desta ação. O texto irá argumentar que a inserção dos canais perceptivos no contexto educativo colabora para um melhor desenvolvimento nos estilos de aprendizagem dos alunos e nos estilos de ensinar de seus professores.

PALAVRAS-CHAVE: Ensino do teatro, canais de percepção, formação de professor.

\section{Abstract}

This text discusses the reflexive action of the drama teacher.

The potential inclusion of studies on the channels of perception (auditory, kinesthetic and visual) is considered as part of this action.

The text argues that the inclusion of perceptual channels in the educational context contributes to a better development of the students' learning styles and their teachers' teaching styles..

KEYWORDS: Theatre teaching, perception channels, teacher's training.

\footnotetext{
${ }^{1}$ Mestre em Teatro pela Universidade Estadual de Santa Catarina - UDESC, professor do Curso de Licenciatura em Teatro da Faculdade de Artes do Paraná - FAP, membro do GT Pedagogia do Teatro \& Teatro e Educação da Associação Brasileira de Pesquisa e Pós-Graduação em Artes Cênicas - ABRACE e integrante do Grupo de Pesquisa Arte, Educação e Formação Continuada na Linha de Pesquisa Arte, Sociedade e Diversidade Cultural na FAP. rossetorobson@gmail.com.
} 
tualmente, em qualquer referência que se faça ao ensino, é com frequência mencionada a reflexão como algo a ser alcançado, como um determinismo no espaço da Academia, especialmente nas licenciaturas. $\mathrm{O}$ refletir é premissa básica para a construção do saber, a prática reflexiva deve ser uma ação permanente e adjacente aos conhecimentos propostos no currículo. O objetivo deste trabalho, nesse sentido, é questiona o processo de formação pedagógica do professor a partir da necessidade da inclusão de uma prática reflexiva, para ponderar, a seguir, sobre como as implicações que o conhecimento sobre os canais de percepção poderá auxiliar nesta ação, qual seja, o ensino do teatro.

Após concluir a graduação, o professor muitas vezes reproduz os encaminhamentos metodológicos apreendidos durante o processo de formação. Conforme Hernandez (1998), quando o professo aprende um esquema de ação tenta logo aplicá-lo, baseando-se apenas na sua própria experiência. Deste modo, evidencio que um dos grandes desafios do trabalh pedagógico é incluir na formação deste profissional o hábito de uma prática reflexiva, de modo que ele não se torne um mero reprodutor de teorias e técnicas de ensino.

Infelizmente, as condições de trabalh oferecidas para o professor não produzem o apoio necessário para uma ação com qualidade, especialmente no que diz respeito à disponibilidade de tempo. Não importa a área do professor, em se tratando de educação básica, ele administra, em geral, várias turmas. Esclareço que no administra está implícito o planejar as aulas, as reuniões pedagógicas, a correção de provas rabalhos, além de cursos de capacitação ou pesquisas próprias; pois um profissional que se diz reflexivo, não pode parar de estudar. No entanto, às vezes não há tempo para continuar a aprender, uma vez que muitos professores lecionam nos três turnos: manhã, tarde e noite.

Mas, em relação ao trabalho específi- to escolar, essa jornada tende a dobrar. O currículo da escola contempla duas aula semanais de arte, isso ocorre quando a escola cumpre com a legislação e compreen de a seriedade das artes no currículo. De outro modo, é recorrente notar, escola configuram os conteúdos artísticos unicamente numa aula semanal, e, infelizmente no ensino médio às vezes são suprimida as aulas de arte. Diante desta constatação é preciso ainda registrar que para o professor de arte almejar um digno salário, será preciso que ele lecione em várias escolas, com o intuito de obter uma carga horári por volta de 40 horas semanais. Nesse sentido, contando com o deslocamento entre as escolas, e o elevado número de alunos devido ao aumento de turmas, a jornada de rabalho de fato dobra.

Perante este panorama, como o professor conduz a reflexão em sua prática docente? Perrenoud afirma que "[...] uma parte da ação pedagógica é feita de urgência e improvisação, por meio da intuição, sem realmente apelar a conhecimentos, seja por falta de tempo, seja por pertinência" (2002 p. 81). Para que isso não ocorra, o saber analisar deve permear todo o processo de formação de um professor, para que este profissional entenda o processo reflexivo dentro do espaço acadêmico, e assim possa empreender a reflexão durante a sua permanência na prática do ensino.

Nos cursos de Licenciatura em Teatro, com recorrência ouço comentários do acadêmicos afirmando que as disciplinas de estágio e as voltadas para o ensino do teatro ficam compreendidas como maté rias-'chave' com enfoque reflexivo para a formação do licenciado. No entanto, a formação do professor requer disciplinas que envolvam conhecimentos mais amplos da ciências humanas e disciplinas especializadas na prática do fazer teatral, tais como interpretação e improvisação. O que os alunos entendem de forma gradativa, é que o professor de teatro precisa ter uma formação teórica e prática em disciplinas específicas do campo teatral, associadas a outras disciplinas de áreas distintas. A ponte entre o fazer teatral com o ensino e sua análi- se será feita por cada aluno-professor, que constituirá sua abordagem a partir do que mais the interessou no rol dos conteúdos, uma interface entre o conhecimento específico e geral. Nesse sentido, o aluno desfaz as fronteiras rígidas que, muitas vezes, marcam as disciplinas.

Os conteúdos contemplados no ementário das disciplinas de um currículo compõem a produção cultural humana portanto, estão constantemente sendo elaborados e discutidos. Por isso, exige de professores e alunos a permanente competência de refletir. Para tanto, requer de todos os envolvidos no processo educativo a capacidade de ouvir, dialogar, decodificar, cruzar, organizar, processar. Destaco que todos esses verbos são uma operação aprendida, que devem envolver de form integral a formação docente.

Mesmo assim, o estágio curricular é a priori a primeira aproximação à prática profissional em que o aluno se coloca frente à realidade e, nessa perspectiva, permite a aquisição de um saber, de um saber-faze e de um saber julgar. Nesse sentido, as atividades de estágio requerem uma reflexão a todo o momento, um examinar constant sobre os limites e as possibilidades. Inclusive é possível presumir mudanças na nomenclatura da disciplina denominada de estágio supervisionado, título já arraigado nas licenciaturas do Brasil. Mas,

A mudança de terminologia da paAvra supervisiondo para estro

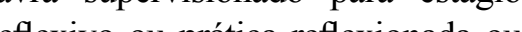
exivo prática rexionada ou orientada somente tera sentido se a compreensão do conceito de estágio estiver levando em conta a reflexão da prática como ponto de partida e de chegada (PIMENTA; LIMA, 2004, p. 114, grifos das autoras)

Embora a denominação da disciplin de estágio ainda permaneça a mesma, que realmente importa é que o estágio se confirma como um campo fértil para a pesquisa. O estágio é o espaço por excelência onde o aluno irá refletir sobre o ensino e
aprendizagem a partir dessa vivência.
Os alunos em processo de formação inicial, segundo Perrenoud (2002), estarão desenvolvendo uma atitude reflexiva: "[... ao analisar protocolos, ao assistir a vídeos, ao observar planejamento didático, ao convidar a escrever um diário, ao trabalhar com situações ou com dilemas ou ao organizar debates." (p. 67). O autor acrescenta ainda que outras atividades provocam uma percepção mais crítica e analítica: “[...] seminários de análise de práticas, grupos de trocas sobre problemas profissionais, acompanhamento de projetos, supervisão auxílio metodológico" (p. 70)

As propostas mencionadas são partíci pes dos procedimentos teatrais nos curso de Licenciatura em Teatro e nas orientações para a prática docente. Por exemplo, no momento da avaliação da linguagem teatral, utiliza-se de protocolos (escrita e desenho), vídeos e fotografias (das improvisações e encenações), situações de dilemas mostrados na cena (discussão sobre as questões culturais, sociais e políticas) Além disso, seminários, diálogos sobre problemas profissionais, orientação de proetos e auxílio metodológico, são atividades á desenvolvidas nas disciplinas de estágio demais disciplinas voltadas para a pedagogia teatral. No entanto, a compreensão destas práticas reflexivas ocorre especialmente em função da postura do professor formador. Concordando com Perrenoud "Só um formador reflexivo pode forma professores reflexivos, não só porque ele representa como um todo o que preconiza mas porque ele utiliza a reflexão de forma spontânea em torno de uma pergunta, de um debate, de uma tarefa ou de um frag mento de saber" (2002, p. 72).

Nesse sentido, primeiramente é fundamental analisar as nossas atitudes enquanto professores formadores dentro de sala de aula, para se obter uma percepção mais acurada das nossas ações. Caso contrário, professor formador pode restringir-se a um discurso automático, pautado em fazeres de 'fórmula certa', sem avaliar constantemente as implicações dos métodos utilizados. 
Como base teórica que norteia essa reflexão, tenho me utilizado da teoria dos canais de percepção, a partir dos estudos da neurolinguística como uma ampliação na possibilidade de análise das proposições metodológicas para a pedagogia teatral junto aos estudantes do Curso de Licenciatura em Teatro da Faculdade de Artes do Paraná - FAP.

\section{OS CANAIS DE PERCEPÇÃO E} A PRÁTICA TEATRAL

Segundo Robbins (2009), recebemos as informações do mundo através de nosso sentidos, visual, auditivo e sinestésico; as pessoas que não possuem algum tipo de deficiência utilizam todos os sentidos podem ser classificadas de acordo com o sistema representacional que mais se manifesta nelas. Assim, "muitas têm acesso seus cérebros principalmente por uma estrutura visual. Reagem às cenas que veem em suas cabeças. Outras, principalment pela auditiva, outras pelas sinestésicas" ( $\mathrm{p}$ 97)

O autor aponta que dentre os canais de percepção ${ }^{2}$ revelamos um com maior destaque, tendo nosso comportamento e nossa comunicação muito ligados a este canal. Usamos os sentidos externos para percebe o mundo e, internamente, reapresentamo o mundo com os mesmos sentidos ao nosso cérebro.

Diante do exposto, sugiro uma hipótese: as preferências de professores e aluno no que concerne à utilização de seus canais de percepção influenciam nos estilo de aprendizagem dos alunos, e os estilos de ensinar de seus professores são um fato gerador de dificuldades de aprendizagem no ensino do teatro. Esta afirmação aponta para o potencial de envolvimento dos canais de percepção no contexto da educação, e enseja a importância da compreensão por parte dos professores das princi-

pais tendências de seus alunos em relação às manifestações dos canais perceptivo para uma reflexão sobre as estratégias de nsino implementadas nas aulas.

Por regra, no início do ano letivo, aplico o teste dos canais de percepção com os alunos para traçar um panorama em fun ção dos canais mais e menos representativos na turma. A partir disso, consigo melhor planejar as aulas em virtude dos dados apontados no teste. Geralmente, não há um canal predominante numa turma. Nesse sentido, o intuito é 'falar' a mesma língua do aluno, e também estimular/aguçar ${ }^{3}$ o canal menos utilizado por este ou aquele aluno. Na prática, o trabalho não é simples, pois se há a incidência de alunos com predominância em diferentes canais, este fato exige do educador uma atenção maior nos encaminhamentos metodológicos.

É possível afirmar que o professor deveria ter os três canais perceptivos com porcentagens iguais, pois assim este profissional iria atuar e propor trabalhos a parti do auditivo, sinestésico e visual. Robbins (1987) afirma que uma mudança qualitativa no processo de ensino e na aprendizagem acontece quando o professor propõe " $[$... alguma coisa visual, alguma coisa auditiva e alguma coisa sinestésica. Deve mostrarlhes coisas, fazer com que ouçam coisas e dar-lhes sensações. [...] deve ser capaz de variar sua voz e entonações, para prender todos os três tipos" (p. 142). Ainda o autor acrescenta que "Quase todos os garotos que fracassam em nossos sistemas educacionais são capazes de aprender. Nós, simplesmente, nunca aprendemos como ensiná-los. Nunca estabelecemos harmonia com eles e nunca igualamos suas estratégias de aprendizado" (p. 236).

Previamente, no ensino do teatro os três canais de percepção são utilizados a todo tempo, pois, em geral, as atividades cênicas envolvem os recursos auditivos, sinestésicos e visuais. Embora o teatro já trate de englobar os canais perceptivos por exce- lência, esse fato não garante o emprego de todos os canais pelo professor. De certo, o docente que tiver um dos canais menos dominante pouco irá envolver este canal em suas práticas. Como se nota, a autoanálise com base nos canais de percepção poderá fazer a diferença na profissão de professor. A propósito, sugiro algumas questões para reflexão:

- Como meu próprio perfil de percepção afeta meu estilo de ensino na sala de aula?

- Como os meus canais de percepção desenvolvidos e subdesenvolvidos afetam aquilo que eu colvco no meu trablho cu educador, ou matem fora dele? elucadr, ou mét de ensip de metodos ou materiais de ensino eu evito porque envolvem o uso do meu canal de percepção subdesenvolvido?

Que coisas eu faço especialmente bem em virtude de um ou de dois de meus canais mais desenvolvidos?

Essas indagações poderão orientar os processos de formação, com o intuito de priorizar uma uniformidade de uso dos canais de percepção no processo de ensino. Tomando-se por base o momento que comecei a pôr em prática o estudo dos canais de percepção, os resultados foram significativos no meu exercício docente. O auditivo é o canal perceptivo menos aguçado e por consequência o menos utilizado por mim, portanto, no processo de preparar uma aula prática de teatro, por exemplo, dava maior importância para os recursos visuais (imagens projetadas, fotografias, observação do espaço, etc.) e para os estírespiração, manipulação de objetos, cheiros, etc.).

A partir disso, percebi que poucas vezes a minha atenção se direcionou para as questões auditivas no ato de preparar as aulas. Com frequência, no momento da aula prática, os recursos sonoros que utilizava eram aleatórios, ou seja, simplesmente colocava uma música durante a dinâmi- ca ou jogo teatral. Posteriormente, a partir de um trabalho reflexivo sobre as minhas colhas para a preparação das atividades, ficou evidente a minha carência de atenção para o som nas minhas opções.

Atualmente, após contínuo esforço para aguçar o meu canal auditivo, ao delinear uma aula, priorizo uma música ou um ruído de acordo com os objetivos do jogo da cena, do exercício. Nesse sentido, consigo melhores resultados. De acordo com Barbosa,

A atividade de aprendizagem vai ser fortemente influenciada pelo uso dos canais de percepção preferenciais do educando, por exemplo, um educador precisa saber falar $\mathrm{n}$ canal auditivo ("auditivêz"), quando explica algo para um educando que prioriza o ouvido para receber informação. $\mathrm{O}$ mesmo educador precisará saber falar no canal visua ("visualêz"), quando tenta ensinar algo para um educando que prioriza o canal visual para internalizar conhecimento. Também precisar cober far no canal sinestésico ("stsaber fatar no canal sinestesico ("sinestesiquez") para conseguir uma compreensão adequada daquilo que está tentando ensinar para um educando que prefere aprender fazendo, sentindo a matéria, cheirando ou provando o conteúdo (2008).

Portanto, é muito importante aprender identificar o canal prioritário do aluno usá-lo para a emissão de mensagem, tornando mais fácil o processo de recepção e entendimento, aumentando a compreens̃o e a aprendizagem. No ensino do teatro, no momento da explicação de um jogo ou exercício, por exemplo, explicar os direcionamentos com exatidão é fundamental pois se alguma dúvida estiver presente, a proposta poderá não surtir o efeito esperado. ${ }^{4}$ Nesse sentido, o professor, ao fa-

Durante as aulas laboratorio, em que alunos ministram atividades teatrais para Sus colegas de sala, é importante notar que no final do processso, durante o mo-
mento da avaliacáo em grupo, os apontamentos geralmente são referentes à fatto celareza nas explicaçóes das metododogiais por aquele que está ministrando a aula. Quando isso ocorre, torna-se evidente no decorrer da aula que os alunos
participes näo permanecem concentrados, numa tentativa de compreender melhor odirecionamennto dado pelo anlunoldocente. 
zer uso dos canais de percepção durante o nossa trajetória de aprendizagem. É preprocesso de ensino, sem dúvida, estimula ciso a disposição do professor para rever o interesse e o entendimento do aluno, um e avaliar constantemente tradições pedaauxílio a mais para um mento das atividades teatrais.

Além disso, utilizar recursos da engrenagem teatral para criar a atmosfera da cena na escola, com instrumentos de percussão, luz, cenários, figurinos, etc., engaja mais o aluno nas proposições da aula. Com uma prática que busca determinar o mesmo universo do espetáculo no espaço da escola, certamente, o professor estará estimulando um efeito estético, obtido com base numa determinada organização de elementos sensoriais. Em decorrência do clima alcançado, os alunos serão envolvidos, provavelmente, através dos canais de percepção por uma recepção subsidiada pelas cores, formas, timbres, movimentos, pelas

Deste modo, os impactos causados na elaboração de encaminhamentos teatrais tomando-se por base as possibilidades sensoriais, em razão das carências artísticas que a escola declara, permitem uma implicação de propostas cênicas mais convincentes. A sedução deve permear o trabalho com o teatro na escola, caso contrário, as propostas cênicas dificilmente atingirão plenamente o envolvimento dos alunos.

O professor em processo de formação precisa valer-se desse desenvolvimento para pesquisar: experimentar e checar alternativas metodológicas. Se os canais de percepção forem utilizados em pesquisa contínua - primeiramente, por meio do autoconhecimento do docente e de seus alunos, para em seguida através de um melhor entendimento sobre os processos de interpretar e organizar os estímulos sensoriais recebidos -, certamente, a qualidade da aula será outra.

Diante disso, faz sentido buscar o desenvolvimento e uma consciência desse processo sob uma forma reflexiva. As experiências significativas provêm das ações diante das sensações, basta identificarmos os caminhos pelos quais foram utilizados os canais perceptivos pelos docentes em

\section{REFERÊNCIAS BIBLIOGRÁFICAS}

BARBOSA, Adelson Cândido. Tecnologias de Transformação do ser. Blumenau: [s.n.], 2008. (Apostila do Curso Estratégias de Aprendizagem, TECTRANS

HERNÁNDEZ, Fernando. Como os docentes aprendem. Pátio $\square$ revista pedagógica, Ano 1, n ${ }^{\circ}$, Fevereiro/Abril, p.9-13, 1998.

PERRENOUD, Philippe. A prática reflexiva no oficio de professor: profissionalização e razão pedagógica. Tradução de Cláudia Schilling. Porto Alegre: Artmed, 2002.

PIMENTA, Selma Garrido; LIMA; Maria do Socorro Lucena. Estágio e Docência. São Paulo: Cortez, 2004. (Coleção docência em formação. Série saberes pedagógicos)

ROBBINS, Anthony. Poder sem limites. Traducão de Muriel Alves Brazil. 11. ed. São Paulo: Best Seller, 2009. 